\title{
Applications of optical fiber assemblies in harsh environments, the journey past, present and future
}

\author{
Melanie N. Ott ${ }^{a}{ }^{a}$, Frank LaRocca ${ }^{b}$ William Joe Thomas ${ }^{\mathrm{b}}$ \\ Robert Switzer ${ }^{\mathrm{b}}$, Richard Chuska ${ }^{\mathrm{b}}$, Shawn Macmurphy ${ }^{\mathrm{b}}$ \\ ${ }^{a}$ NASA Goddard Space Flight Center, Greenbelt Maryland, 20771 \\ ${ }^{b}$ MEI Technologies, 7404 Executive Place, Suite 500, Seabrook, MD 20706
}

\begin{abstract}
Over the past ten years, NASA has studied the effects of harsh environments on optical fiber assemblies for communication systems, lidar systems, and science missions. The culmination of this has resulted in recent technologies that are unique and tailored to meeting difficult requirements under challenging performance constraints. This presentation will focus on the past mission applications of optical fiber assemblies including; qualification information, lessons learned and new technological advances that will enable the road ahead.
\end{abstract}

Keywords: spaceflight, optical fiber, lunar, connector, mars, ISS, communication, mercury, laser

\section{INTRODUCTION}

Optical fiber systems have been utilized in space flight hardware for over thirty years.[1] Starting with the first optical fiber passive in flight environmental testing with the Long Duration Exposure Facility in 1978. In 1989 the Cosmic Background Explorer (COBE) satellite, included several photonic and optical fiber components that functioned accurately enough for the Principal Investigators, John C. Mather of Goddard Space Flight Center and George F. Smoot of that mission to become Nobel Prize laureates in 2006.[2] Over the next decade several NASA missions had baselined optical fiber communication systems including the International Space Station. In 1992 the Small Explorers Program (SMEX) at NASA Goddard Space Flight Center, broke new ground by proving that optical fiber was a viable option for space flight. The SAMPEX, Solar Anomalous and Magnetospheric Particle Explorer was the first mission of the SMEX program which launched in 1992 designed for a 1 year mission duration and is still functional for science data, 16 years later and it utilizes the first GSFC flown optical fiber MIL-STD-1773 communications system as the critical link between the science instruments. In addition to those missions mentioned the following is a summary table that was presented in 1999 at Marshall Space Flight Center as an update after the publication in reference 1 was already released.

Table 1: From 1999, this summary was generated to identify which programs had base-lined optical fiber communications for space flight missions as the link for the critical command and handling data system. For this paper it has been updated to reflect more accurate launch dates

\begin{tabular}{|l|l|l|l|l|}
\hline Project Name & Acronym & Launch Date & Technology & Wavelength \\
\hline Solar Magnetospheric Particle Explorer & SAMPEX & July 1992 & MIL-STD-1773,1 Mbps & $850 \mathrm{~nm}$ \\
\hline Microelectronic and Photonic Test Bed & MPTB & Dec. 1997 & AS1773, 20 Mbps & $1300 \mathrm{~nm}$ \\
\hline Microwave Anisotropy Probe & MAP & June 2001 & AS1773, 20 Mbps & $1300 \mathrm{~nm}$ \\
\hline X-ray Timing Explorer & XTE & Dec. 1995 & MIL-STD-1773,1 Mbps & $850 \mathrm{~nm}$ \\
\hline Hubble Space Telescope, upgrades & HST & Feb. 1997 & MIL-STD-1773,1 Mbps & $850 \mathrm{~nm}$ \\
\hline Photonic Space Experiment & PSE & proprietary & MIL-STD-1773,1 Mbps & $850 \mathrm{~nm}$ \\
\hline Tropical Rainforest Measuring Mission & TRMM & Nov. 1997 & MIL-STD-1773,1 Mbps & $850 \mathrm{~nm}$ \\
\hline
\end{tabular}

Over the decade to follow more varied applications of optical fibers were utilized at NASA Goddard Space Flight Center for science instrumentation. In addition to what is listed above, the International Space Station managed by Johnson Space Center, used a Boeing designed optical fiber data bus called the High Rate Data Link using $1300 \mathrm{~nm}$ graded index multimode optical fiber links and an enhanced MIL-STD-38999 connector with MIL-T-29504 termini. The MIL-STD-

\footnotetext{
${ }^{1}$ Melanie.n.ott@nasa.gov, 001-301-286-0127, misspiggy.gsfc.nasa.gov/photonics
} 
1773 optical fiber links typically used the MIL-STD-38999 and MIL-T-29504 termini where in other cases the customized 140 micron Johanson FC type connector was used. This connector is no longer recommended for new space flight missions since Johanson has sold the optical fiber products line. The cables that were used during those missions is also obsolete and no replacement to the exact dimensional specifications of the GSFC qualified Brand Rex OC1008 or the International Space Station's version of the Brand Rex OC1416. However, the study towards finding a suitable replacement is underway.

In addition to the projects mentioned above, the Code 562 Photonics Group at NASA Goddard Space Flight Center, has been involved in a variety of optical fiber system implementations over the past decade since the MIL-STD-1773 decade. The following is a summary table of how we have enabled flight hardware and how.

Table 2: NASA Goddard Space Flight Center Photonics Group Heritage with Space Flight Optical Fiber Subsystems over the past decade.

\begin{tabular}{|c|c|c|c|c|c|c|}
\hline Project & Dates & Design & $\begin{array}{c}\text { Qualification } \\
\text { Permance over Harsh } \\
\text { Environment }\end{array}$ & Manufacturing & Integration & Failure Analysis \\
\hline ICESAT, GLAS, & $1997-2005$ & $\mathrm{X}$ & $\mathrm{X}$ & $\mathrm{GSE}$ & & Prototype \\
\hline ISS & $1998-2008$ & & & & & $\begin{array}{c}\text { Vendor/ } \\
\text { Flight }\end{array}$ \\
\hline ISS - HDTV & 2003 & $\mathrm{X}$ & $\mathrm{X}$ & FLIGHT & & \\
\hline Fiber Optic Data Bus & $1997-2000$ & $\mathrm{X}$ & $\mathrm{X}$ & & & \\
\hline Messenger - MLA, & $2001-2004$ & $\mathrm{X}$ & $\mathrm{X}$ & FLIGHT & $\mathrm{X}$ & \\
\hline $\begin{array}{c}\text { Sandia National Labs } \\
\text { (DOE) }\end{array}$ & $1998-2008$ & & FLIGHT & & & $\begin{array}{c}\text { Vendor/ } \\
\text { Flight }\end{array}$ \\
\hline $\begin{array}{c}\text { ISS-Express Logistics } \\
\text { Career }\end{array}$ & $2006-2009$ & $\mathrm{X}$ & $\mathrm{X}$ & FLIGHT & $\mathrm{X}$ & \\
\hline Air Force Research Lab & 2003,2008 & & $\mathrm{X}$ & & & \\
\hline Shuttle Return To Flight & $2004-2005$ & & & FLIGHT & & \\
\hline $\begin{array}{c}\text { Lunar Orbiter Laser } \\
\text { Altimeter }\end{array}$ & $2003-2008$ & $\mathrm{X}$ & $\mathrm{X}$ & FLIGHT & $\mathrm{X}$ & Prototype \\
\hline $\begin{array}{c}\text { Mars Science Lab } \\
\text { ChemCam }\end{array}$ & $2005-2008$ & $\mathrm{X}$ & $\mathrm{X}$ & FLIGHT & $\mathrm{X}$ & Vendor \\
\hline Laser Ranging, LRO & $2005-2008$ & $\mathrm{X}$ & $\mathrm{X}$ & FLIGHT & $\mathrm{X}$ & Prototype \\
\hline Fiber Laser IIP/IRAD & $2003-2006$ & $\mathrm{X}$ & $\mathrm{X}$ & QUAL & & \\
\hline ESA/NASA SpaceFibre & 2008 (TBD) & & $\mathrm{X}$ & QUAL & & \\
\hline
\end{tabular}

GSE = Ground System Equipment Assemblies Suport

FLIGHT = Actual flight hardware was the subject material.

Vendor $=$ Vendor supplied hardware

In Table 2 the project name or acronym is listed with the dates of development and the identification of which type of services were performed by the group. In the events that the Photonics group was requested to perform failure analysis during the late stages of integration the root cause was usually a lack of failure mode risk mitigation during the design/development process, quality documentation or handling issues. Most concepts are born from a creative design group who know more about how to capture science data and less about the intricacies of space flight material choices and how to implement appropriate risk mitigation techniques and keep an effective schedule. Too many times we have found that vendors and contractors that make space flight hardware deliveries did not invite well versed failure mode physicists and engineers to the design table. What followed later was that the optical fiber assemblies were viewed similar to copper wire cable harnessing instead of micro-optical devices. This fallacy has led to many issues during integration that span from design to handling during flight integration. 


\section{DISCUSSION OF OPTICAL FIBER SUBSYSTEMS}

\subsection{Development of subsystems for harsh environments}

Based on the extensive work over the past decade related to flight builds and failure analysis of other providers that are not in the high volume production of space flight hardware, the group has development flow from concept to delivery.

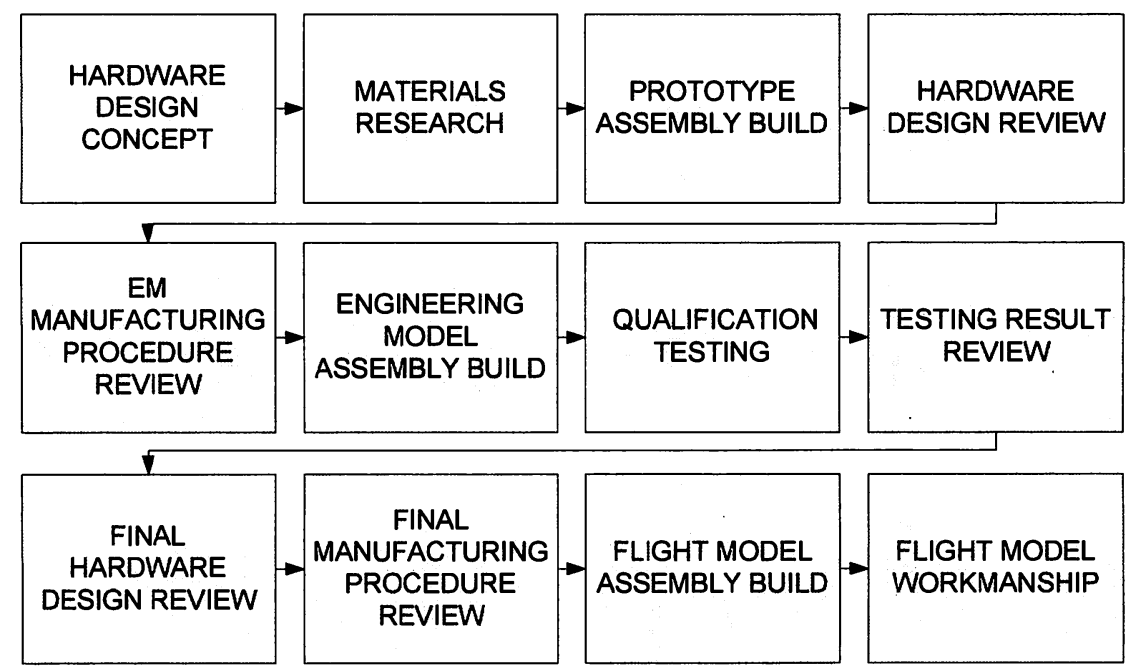

Figure 1: Photonics Group Concept to Delivery Flow

Our approach was developed by years of experience and anl understanding of risk mitigation for failure modes vs. schedule for typical space flight projects--and the fact that nearly all new technologies are commercial off the shelf and must be tested and developed as such in order to achieve the least amount of anomalies by the time flight manufacturing begins. A long list of quality documentation from unique developmental endeavors is required for mission success, whether it be from a vendor or another government manufacturing provider.

\subsection{Approach to Commercial Technologies}

Something engineering designers are wise to keep in mind is the following; being well educated about the physics of failure is not always feasible for vendors that can not afford to pay the bill to go through extensive testing as they once did for the military for compliance to the military specifications. This is essentially what the space flight development engineer is doing when specifying to a vendor that they must comply with a long list of Military Standards. There is no incentive for a vendor to use precious resources to extensively test their commercial components to a set of unusually harsh environmental parameters when the customer is only going to purchase a few on a one time, one-of-a-kind instrument.

The expectation that a vendor is obligated to meet a large amount of difficult demands for a space flight customer for the purpose of stating that this partnership exists, is not beneficial to the vendor in producing the business it would take to justify the costly expenditure. It is important that even the component engineers understand that to achieve high reliability that they, themselves need to be responsible for making that happen between analysis and testing and working very closely with the vendors to provide guidance that will enable success.

Most commercial processes that are designed for high volume, can not be changed to accommodate a space flight build of a particular component, therefore the analysis especially with regards to processes and construction can lead to suggestions to the vendor however, do not expect that if the process change involves extra money spent on the part of the vendor its not likely going to be feasible and if it is it will no doubt result in a very costly non-recurring engineering fee that the space flight program will need to fund. The old saying "you can get a cheap job done but it won't be good or you can get a good job done but it won't be cheap" needs to be considered when approaching the commercial industry 
about using commercial parts in space. Many vendors are even going away from compliance with the Telecordia certifications since the majority of their customers today are not commercial telecommunications providers but are industrial customers using light for manufacturing of their products. Even if a part was originally part of the telecommunications components base 7 years ago, you may be surprised to find that the same exact part being produced today is no longer being tested to Telecordia standards even if was in the past.[5]

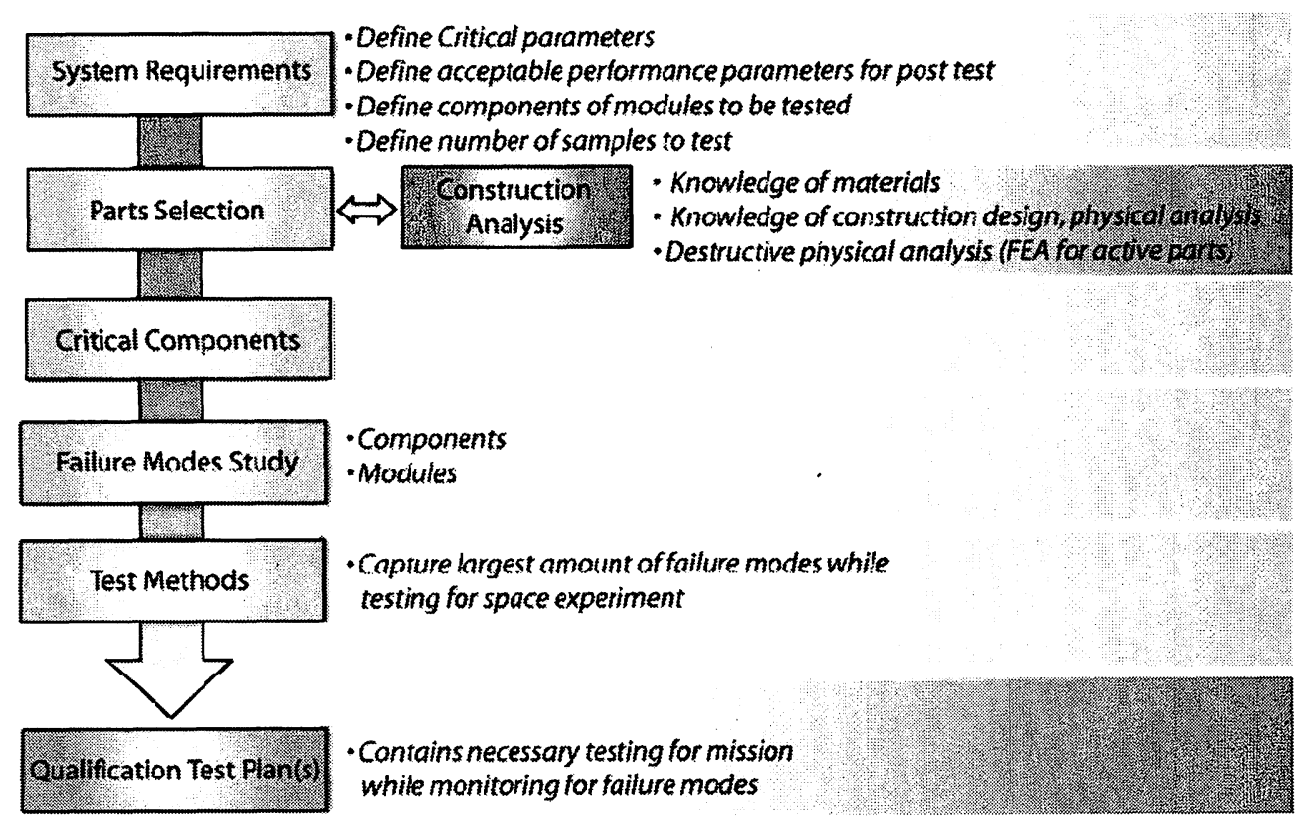

Figure 2: Steps to a Qualification Test Plan; NEPP Technology Assurance Approach [6]



Figure 3: COTS Qualification Plan Approach [6]

Figures 2 and 3 summarize the steps in development of reliable commercial optical fiber assemblies and then how to qualify or perform requirements validation on the engineering models such that the flight models will be ready for the mission. Reference 5 presents a more comprehensive explanation of the details. Many of those details are reflected in the product flow of Figure 1. If there is one key item of note from the above figures it would be; having a good understanding of how materials affect other materials when performing packaging of optical fiber hardware can save a great deal of funding later in development and integration. 


\section{FLIGHT EXAMPLES AND CURRENT TECHNOLOGY}

In the last decade two connector types have emerged as harsh environments, the USConec MTP array connector type for parallel communications using multimode ribbon fiber and the Diamond AVIM DIN type connector with active alignment for single or multimode applications. The Diamond AVIM was qualified for flight applications back during the mid 1990's by Lockheed Martin [7] and continued to be used and qualified by NASA and ESA.

The first time NASA Goddard used the AVIM connector was for single and multimode interconnections on the Ice, Cloud, and land Elevation Satellite (ICESAT) GeoScience Laser Altimeter (GLAS). Four different types of fiber were used, two types of multimode and two types of single mode. In addition, a 2 kilometer single mode optical fiber delay line used for on orbit calibration.[8] During the development of GLAS, several optical fiber candidates were tested for radiation induced scintillation effects and no results that would effect performance were detected.[9] The standard AVIM connector continued to be used on the Mercury Laser Altimeter, Shuttle-Return-to-Flight High Definition heat tile sensor camera.

The MTP connector was developed for communications applications and to be compatible with the newly available Vertical Cavity Surface Emitter Laser (VCSEL) technology that arrived in the mid 1990's. The first NASA GSFC mission scheduled to fly this connector was the Spaceborne Fiber Optic Data Bus (FODB). Several qualification studies on the connector and cable assembly were conducted for NASA and the Department of Energy and published in the past decade. [10-12]

\subsection{The Mercury Laser Altimeter (MLA)}

The MLA was a laser altimeter launched in 2004 to measure the topography of Mercury. As part of the receiver optics system, four individual step index multimode fiber were linked from the receiver optic telescopes to the MLA individual detectors. The AVIM connector with FLEXLITE cable from W.L. Gore was used to provide the optical fiber links. For the instrument. The requirements validation testing was conducted prior to flight manufacturing and published in reference 13 .
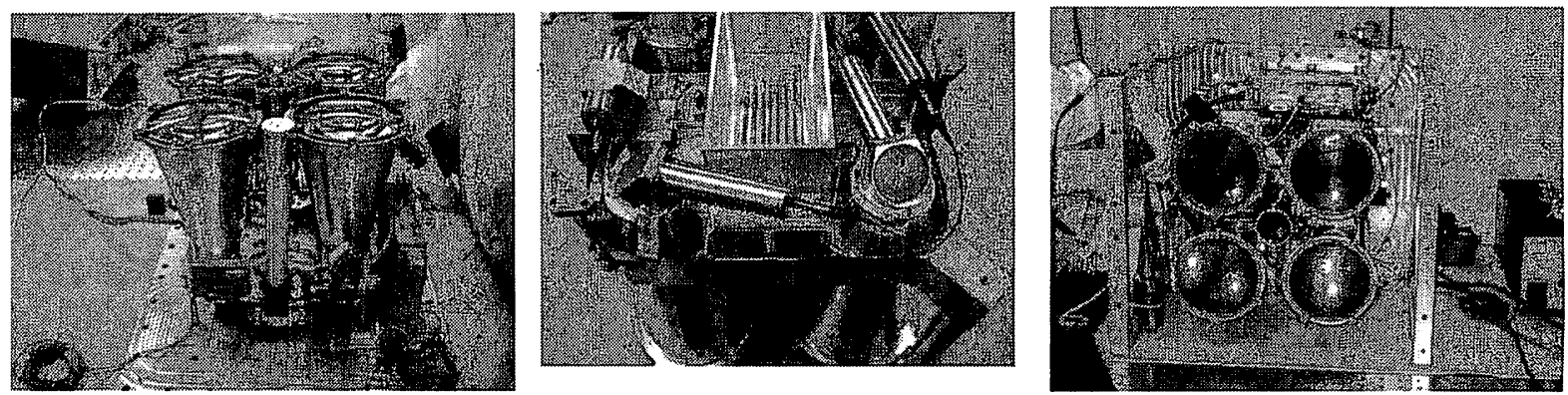

Figure 4: The Mercury Laser Altimeter consisted of four telescopes with fiber coupled form each to four individual detectors.[13]

An experiment that was conducted with the Mercury Laser Altimeter in May 2005, provided the assurance that laser communications could traverse long distances through space. A laser system built and designed at GSFC called "HOMER" [14] located at NASA's Goddard's Geophysical and Astronomical Observatory was used to contact the MLA aboard MESSENGER on its way to Mercury and established a ranging link across 24 million kilometers. [15-16]. This gave the Principal Investigators new insight into what was possible. This will be discussed later when the subject of the Lunar Reconnaissance Orbiter (LRO) adds a laser ranging capability to the instrumentation already planned.

\subsection{The Lunar Orbiter Laser Altimeter on LRO}

The Lunar Orbiter Laser Altimeter is part of the instrument suite on the Lunar Reconnaissance Orbiter and where the Mercury Laser Altimeter consisted of four telescopes and is designed to be capable of measuring with a $0.5 \mathrm{~m}$ precision, LOLA will consist of only one telescope and provide a 0.1 meter precision. Both altimeters were designed to function using pulsed $1064 \mathrm{~nm}$ lasers and measure the timing of the reflections with short duration pulses. LOLA uses a diffractive optical element to split a single laser beam into five separate pulsed beams with five very precisely positioned optical fibers behind the receiver optics to link each beam to its designated detector. The time of flight measurements 
provide ranging information, the pulse spreading corresponds to surface roughness, and the return energy provides surface reflectance. The five spots will provide slopes along and across the orbit track. [17] In addition, one of LOLA's detectors will be used to monitor the laser ranging signals received by a $532 \mathrm{~nm}$ pulsed laser from the NASA Goddard Greenbelt facility. Figure 4 shows the flight instrument next to an artist's rendition of the LOLA instrument and the LRO.
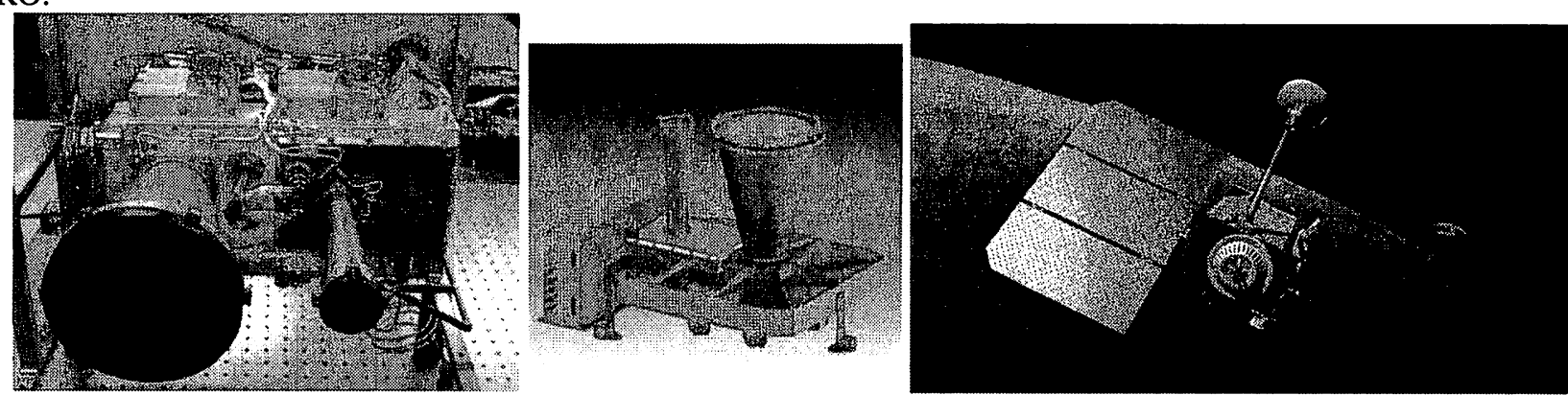

Figure 4: a) LOLA flight instrument, b) artists drawing of LOLA instrument, c) artists drawing of LRO.

In order to enable the five spots reflected back to the instrument a fiber array was developed and is first in the world of its type since the entire array is packaged into a single polarization maintaining type Diamond AVIM connector. Figure 5 shows the endface pattern of all $5200 / 220$ micron step index optical fibers in a tightly tolerance pattern along with a picture of one of the LOLA flight assemblies.


Figure 5: a) LOLA array 200X magnification view of the the optical fiber connector endface, b) the LOLA flight bundle array.

In order to assure of high reliability for this application, many qualification tests were conducted and the results of which are contained in reference 18. As a result of the qualification testing, the flight procedures were rewritten and once again test articles were retested to qualification levels. For LOLA, the $20 \mathrm{grms}$ acceleration profile was used to qualify the engineering models. For flight a smaller acceleration profile was used for workmanship purposes. Figure 6 shows the production testing flow required for the LOLA flight hardware as a result of qualification testing.

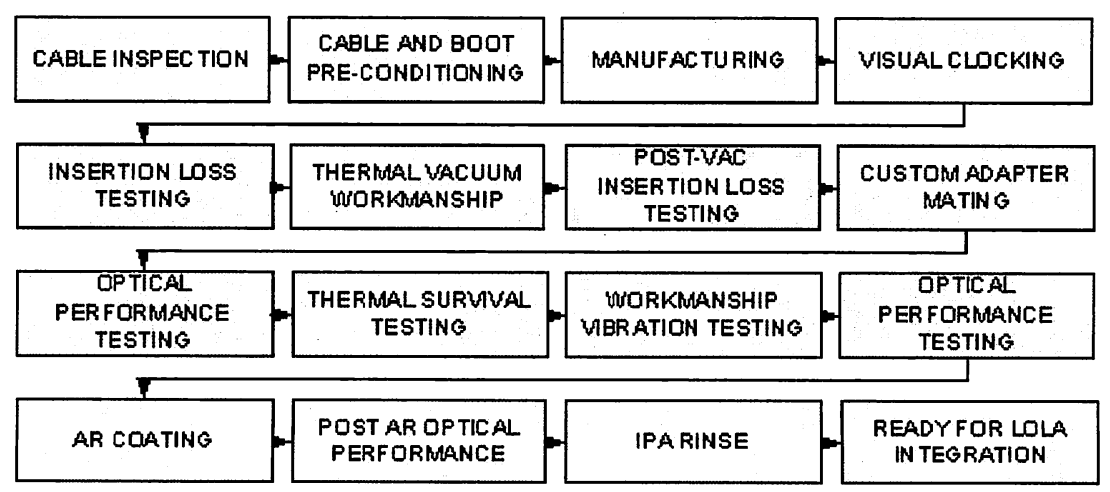

Figure 6: LOLA Optical Fiber Bundle Array Assembly Delivery Flow

This assembly is the first of its kind to be fully qualified for harsh environments and integrated into a single connector on a flight instrument. The LOLA flight assembly integrated to the instrument was tested for three times for random 
vibration 1) protoflight workmanship, 2) instrument level qualification and 3) LRO space craft level qualification. The flight assemblies passed all tests.
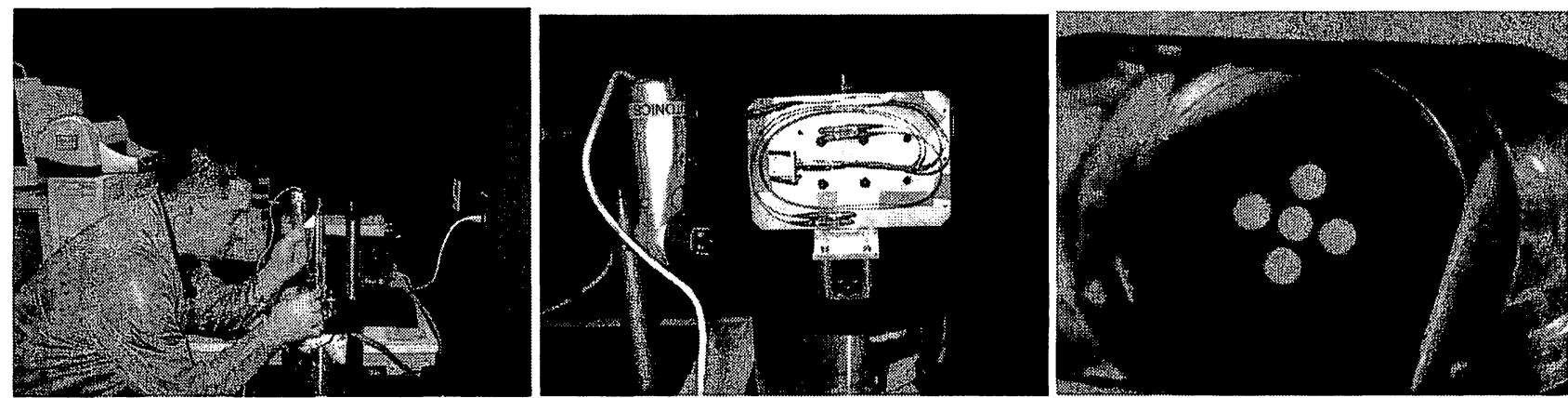

Figure 7: LOLA flight workmanship random vibration testing a) Frank LaRocca performs vibration testing, b) LOLA flight article on the vibration fixture, c) flight assembly final inspection post vibration testing

\subsection{Laser Ranging on the LRO}

After the success of ranging with the MLA, the "Laser Ranging" project was added to the LRO mission instrument suite. A small telescope was mounted to the High Gain Antenna System (HGAS) on the LRO and required an optical link from behind the telescope across the HGAS gimbals, down its boom, around the deployment mandrel and across the space craft to LOLA detector channel 1. Figure 8 illustrates the concept.[19]

\section{LR Operations Overview}

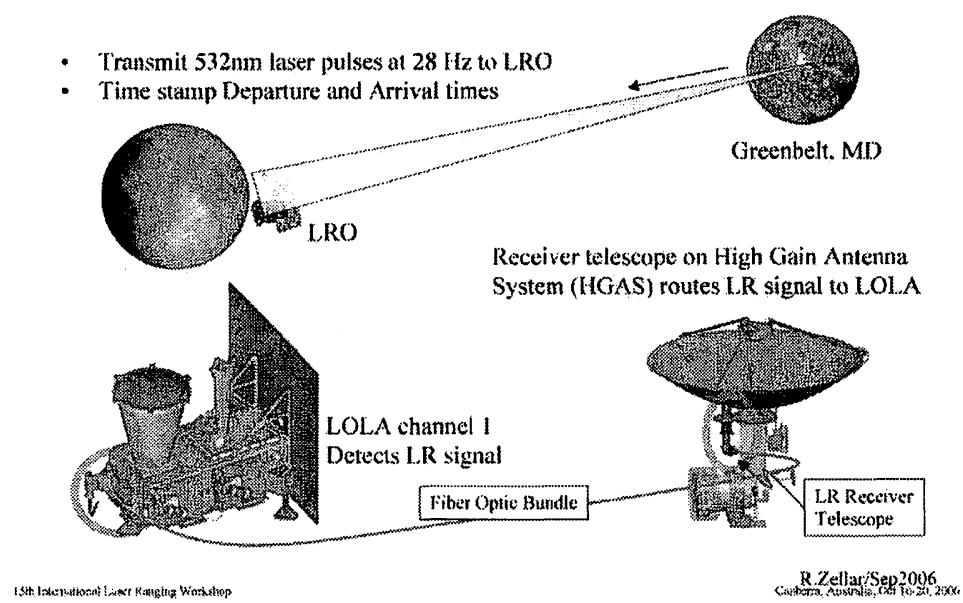

Figure 8: Laser Ranging operations summary

Figure 10 diagrams the flight system components. To complicate matters two interconnections were required; one at the interface between the steering HGAS gimbals and one after the boom deployment mandrel at the space craft. The solution to the challenge was developed by the Photonics Group at NASA GSFC to be a seven optical fiber array bundle assembly set approximately 10 meters long. Figure 9 shows the unique hardware used for this application and reference 20 presents the qualification data for the engineering models. Reference 21 contains the information regarding integration of the flight hardware. Early on in the development process, the cold requirement was being held at $-75^{\circ} \mathrm{C}$. This requirement was incorporated into the choice of using stainless steel 416 instead of the stainless steel 303 material we had originally planned to use. Even though the thermal requirements were later altered based on thermal conducting tape being used for control, survival testing was conducted down to $-75 \mathrm{C}$ to assure survival of the assemblies and the assemblies passed all qualification testing with nominal changes in performance.[20] Another difficult requirement for the team was the way in which the fiber cables would be routed through the HGAS gimbals. Essentially the gimbals 
contain cable wraps that coil and uncoil the cables to enable the rotation of the antenna for beam steering. Material selection and material compatibility was an enormous issue during development.
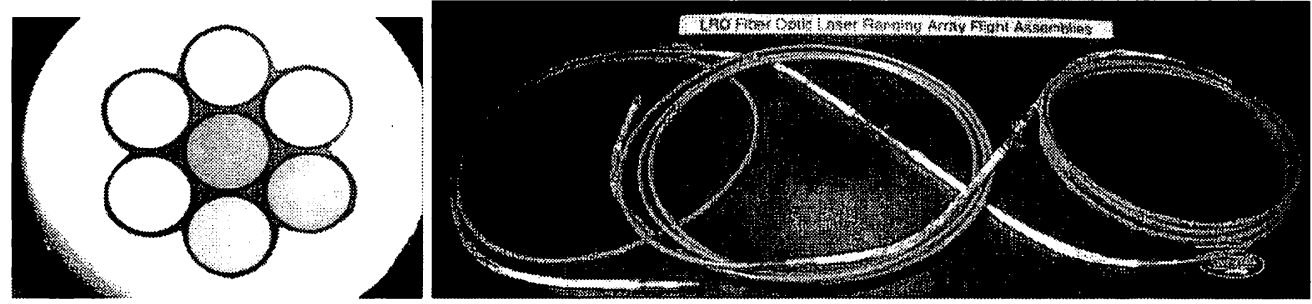

Figure 9: LRO Laser Ranging Assemblies

\section{LR Flight System Components}

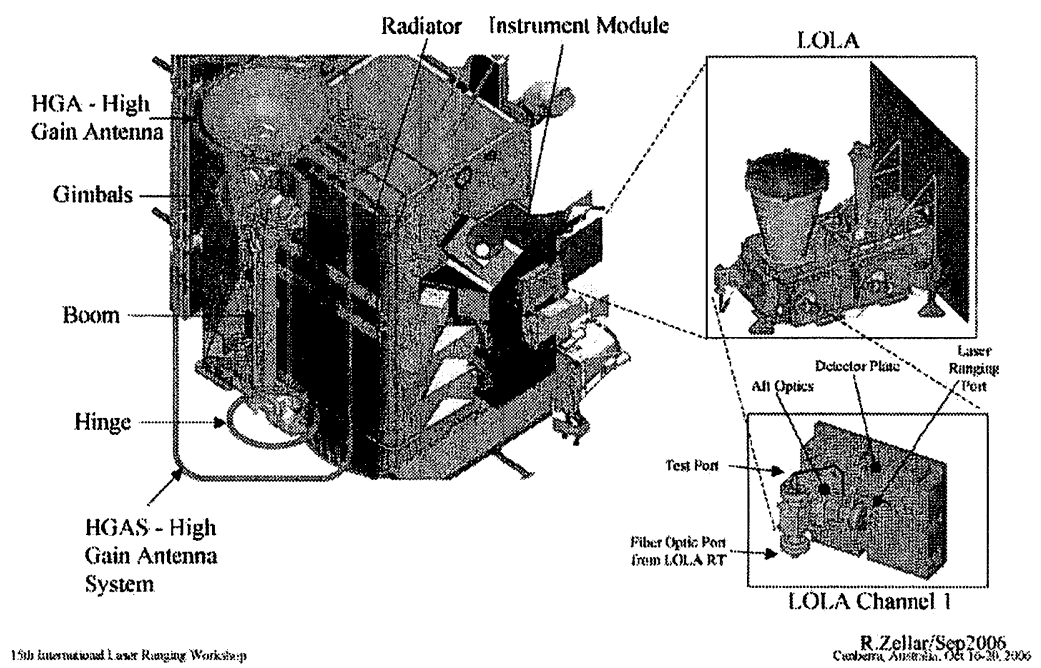

Figure 10: Laser Ranging flight components for optical fiber linkage.

As mentioned previously, documentation is a key item to ensure reliability of the flight hardware. Table 3 lists the documentation required for the Laser Ranging optical fiber bundle assemblies.

Table 3: Quality documentation for the Laser Ranging Flight Assemblies.

\begin{tabular}{|l|c|}
\hline Document Title & Document Number \\
\hline Thermal Pre-conditioning on Flexlite 200/220 $\mu \mathrm{m}$ fibers for flight application & LOLA-PROC-0137 \\
\hline Preconditioning Procedure for AVIM Hytrel Boots for LOLA fiber optic assemblies & LOLA-PROC-0138 \\
\hline Diamond AVIM PM Kit Pre-Assembly Inspection & LOLA-PROC-0104 \\
\hline Ferrule Polishing \& Ferrule/Adapter Matching Procedure & LOLA-PROC-0139 \\
\hline $\begin{array}{l}\text { Assembly and Termination Procedure for the Laser Ranging Seven Fiber Custom PM Diamond AVIM } \\
\text { Array Connector for the Lunar Reconnaissance Orbiter }\end{array}$ & LOLA-PROC-0112 \\
\hline Compression Test Procedure for Fiber Optic Connector & \\
\hline Active Optical Power Optimization Procedure for The Laser Ranging Optical Fiber Array Assemblies & LOLA-PROC-0141 \\
\hline Laser Ranging Fiber-Optic Bundle Optical Test Procedure & LOLA-PROC-0110 \\
\hline Insertion Loss Measurement Procedure for The Laser Ranging Optical Fiber Array Bundle Assemblies & LOLA-PROC-0107 \\
\hline Mating of Two LR 7-Fiber Optical Fibers Using Cleanable Adapter & LOLA-PROC-0142 \\
\hline Cutting Back The Kynar Strain Relief For Integration & LOLA-PROC-0143 \\
\hline Fiber Optic Bundle Inspection and Insertion Loss Measurement & LOLA-PROC-0148 \\
\hline
\end{tabular}

The flight assemblies have been integrated to the space craft and have passed all qualification testing. LRO is scheduled for launch later this year. 


\subsection{Mars Science Laboratory ChemCam}

For the Mars Science Lab, the ChemCam the Photonics Group in cooperation with Jet Propulsion Laboratory (JPL) team: Chris Lindensmith, Charles Hays, Richard Rainen, Edward Miller and Principal Investigator Roger Weins from Los Alamos National Labs developed optical fiber assemblies for the integration. Once again, as with LRO the mission the mechanical requirements included routing the optical fiber assemblies through moving gimbals and down a boom. During the early stages of development the MSL thermal requirements for the ChemCam assemblies were $-143^{\circ} \mathrm{C}$ for survival lower limit and $+110^{\circ} \mathrm{C}$ for the high limit. The high thermal survival temperature was set to accommodate a decontamination vacuum bake-out that would be necessary for all MSL hardware.
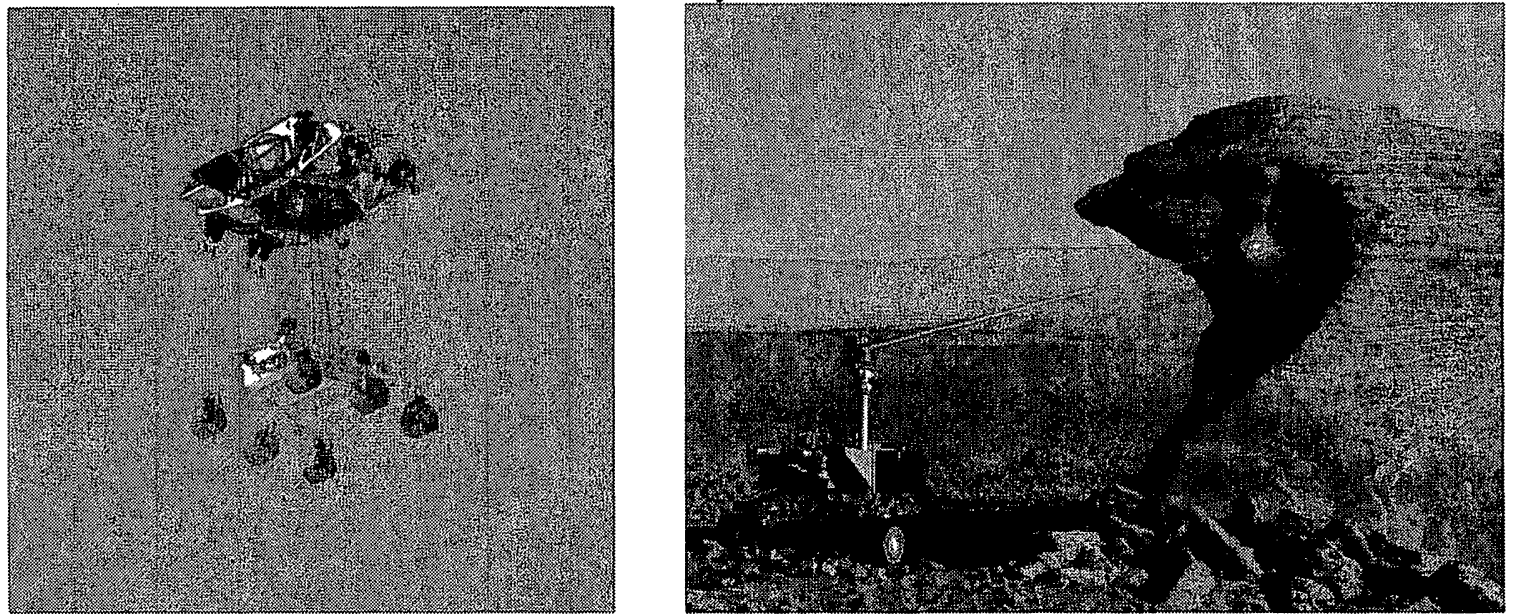

Figure 11: Artists rendition of Mars Science Lab ChemCam[22]

While thermal bake-outs are considered a typical protocol for all space flight instrumentation the thermal limit on the hot end of the spectrum is usually less. Again, for its superior thermal performance the AVIM connector along with the W.L. Gore FLEXITE cable were the parts of choice for another unique application. Some qualification testing was conducted by the Photonics Group of GSFC while other tests were conducted at JPL. By the time thermal life testing started the requirements had changed to $-55^{\circ} \mathrm{C}$ to $+50^{\circ} \mathrm{C}$, with the high temperature bake-out still to occur at $+110^{\circ} \mathrm{C}$.
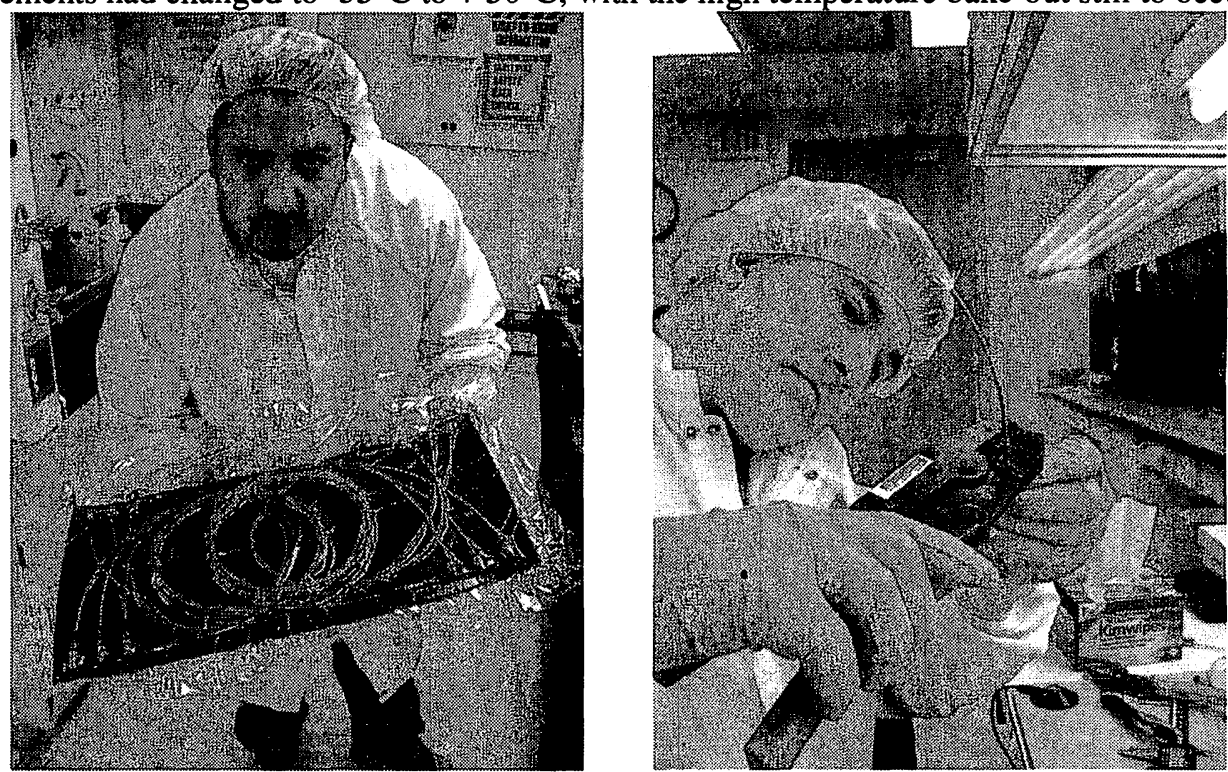

Figure 12: Frank LaRocca and Richard Chuska manufacture and deliver the flight optical assemblies for MSL.

Again, as with LRO, the lower limit of the survival thermal range was controlled through the use of neptape for conductive heating. The quality documentation was extensive and presented in Table 4. 
Table 4: The quality documentation for manufacturing and delivery of the ChemCam optical fiber assemblies.

\begin{tabular}{|c|c|}
\hline Document Name & 562-PHOT-QAD-MSL-FON1482-INSP \\
\hline Optical Cable Inspection & 562-PHOT-QAD-MSL-THERM-PC \\
\hline Cable Thermal Pre-Cond & 562-PHOT-WOA-MSL-BOOTS \\
\hline Polymers Degas & 562-PHOT-QAD-MSL-RAD (12-day worst-case cobalt60 radiation testing) \\
\hline $\begin{array}{l}\text { Mission Survival Radiation Total Dose } \\
\text { Testing }\end{array}$ & $\begin{array}{l}\text { 562-PHOT-QAD-MSL-VIBE } \\
\text { (7.9grms to } 14.4 \mathrm{grms} \text { step-up vibration on selected samples) }\end{array}$ \\
\hline Mission Survival Vibration Qualification & $\begin{array}{l}\text { 562-PHOT-QAD-MSL-THERM-CYCLE } \\
\text { (100+ cycles including planetary bake-out) }\end{array}$ \\
\hline Mission Survival Thermal Cycling Testing & 562-PHOT-QAD-MSL-MAN-92 (Patch Cables) \\
\hline FC Cable Manufacturing (non-flight) & 562-PHOT-QAD-MSL-MAN-92-332 (Prototype Development) \\
\hline AVIM Cable Manufacturing (non-flight) & 562-PHOT-QAD-MSL-MAN-332-EM (Eng Models) \\
\hline AVIM Cable Manufacturing (flight-like) & 562-PHOT-QAD-MSL-MAN-332-FM (FLIGHT and FLIGHT Spares) \\
\hline AVIM Cable Manufacturing (FLIGHT) & 562-PHOT-QAD-MSL-INS-92-332 \\
\hline Insertion Loss Testing (All-Cables) & 562-PHOT-QAD-MSL-WKM-92-NONFL (Non-flight workmanship) \\
\hline Non-flight Cable Workmanship Testing & 562-PHOT-QAD-MSL-WKM-332-FLIGHT (FLIGHT workmanship) \\
\hline FLIGHT Workmanship Testing & GSFC-PHOTONICS CABLE TRAVELER REV 080101 \\
\hline MSL CABLE TRAVELER & GSFC-PHOTONICS ENGINEERING DOCUMENT REVIEW \\
\hline Engineering Documents Review & GSFC-PHOTONICS PRE-SHIPMENT PROCEDURE CHECKLIST \\
\hline Pre-Shipment Inspection Checklist & GSFC-PHOTONICS PACKING PROCEDURE CHECKLIST \\
\hline Cable Packing Procedure Checklist & 562-PHOT-QAD-MSL-FON1482-INSP \\
\hline
\end{tabular}

The Mars Science Lab is scheduled to launch in 2009.

\subsection{Express Logistics Carrier on International Space Station.}

The Express Logistics Carrier is being developed as a "smart" warehouse for the International Space Station. The communication "brains" of the warehouse or the Flight Control Unit (FCU) will be transmitting data to and from the ISS. The FCU will provide: remote terminal to the ISS, bus controller for up to two science experiments, command distribution and telemetry collection for up to two science experiments, ethernet to High Rate Data Link (HRDL) playback of science data experiments, command distribution and telemetry collection for the Experiment Control Module and the Power Module. The High Rate Data Link (HRDL) is an optical fiber communications bus developed for ISS by Boeing. The transceivers for the optical fiber communication for the ELC FCU communications with the HRDL are being manufactured by Space Photonics Incorporated. Space Photonics or SPI originally worked under the company name of Optivision over ten years ago as the transceiver provider for the Space Borne Fiber Optic Data Bus also known as FODB. The MTP connector was qualified for the maiden voyage of this communications system but the flight for FODB was cancelled during qualification testing of the subsystem components due to instrument re-scoping on Earth Orbiter 1 .
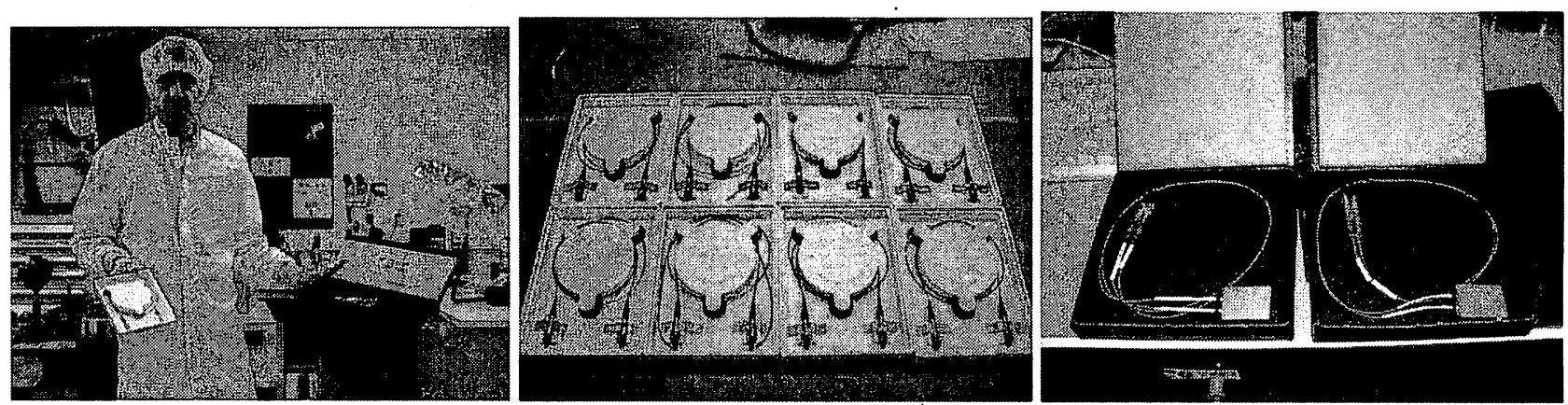

Figure 13: a) Robert Switzer holds the manufactured assemblies b) optical fiber assembiles for the SPI transceiver ready for shipment, c) SPI transceivers with the optical fiber pigtails packaging completed.

The standard AVIM with custom drilled pilz ferrules and FLEXLITE combination was selected for the SPI transceivers and manufactured by the Photonics Group. The fiber had to match that of the ISS HRDL and therefore was $100 / 140$ micron graded index optical fiber manufactured by Nufern. At time the engineering models are being tested for 
compatibility with the HRDL system before the flight models will be built. The remaining cable harnessing will be built by the photonics group using the ISS custom cable still in supply and the ISS version of the MIL-STD- 38999 with MILT-29504 termini with hybrid assemblies to fan out the 38999 terminations to the AVIM adapters at the FCU interface.

\section{FUTURE MISSIONS AND TECHNOLOGIES}

It is expected based on current requests that single connector arrays will continue to be in high demand due to the successful development of the custom array bundles developed for both LOLA and Laser Ranging on LRO. No longer will designers be constrained by having the receiver detectors near the transmitters. Fiber lasers are a viable technology for harsh environments and terminations will be necessary to accompany those. The NASA Photonics Group continues to encourage emerging technologies through development efforts for flight projects and through evaluation programs of vendor provided technologies through the NASA Parts and Packaging Program.

The MTP is expected to continue as a viable option for multimode communications. The group is continuing the evaluation of this connector to provide greater thermal stability of the MTP terminations since the "how" of an optical fiber assembly procedure is just as important as the "what" of an optical fiber assembly.
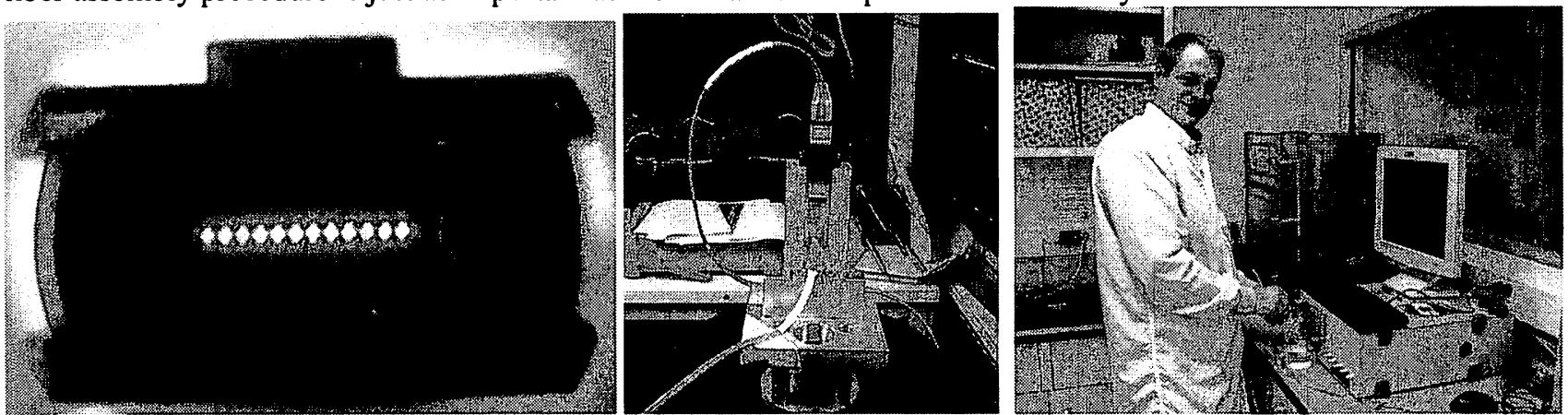

Figure 14 a) MTP connector endface, b) an MTP interconnection begin evaluated for vibration performance, c) Joe Thomes conducts insertion loss testing on the MTP assemblies for a DOE qualification study.

In addition to the MTP connector for communication purposes, science instruments will still require arrays of various types for moving light from one location on the instrument to another. Single connector arrays tailored to a variety of harsh environments and remote locations will continue to be of interest.
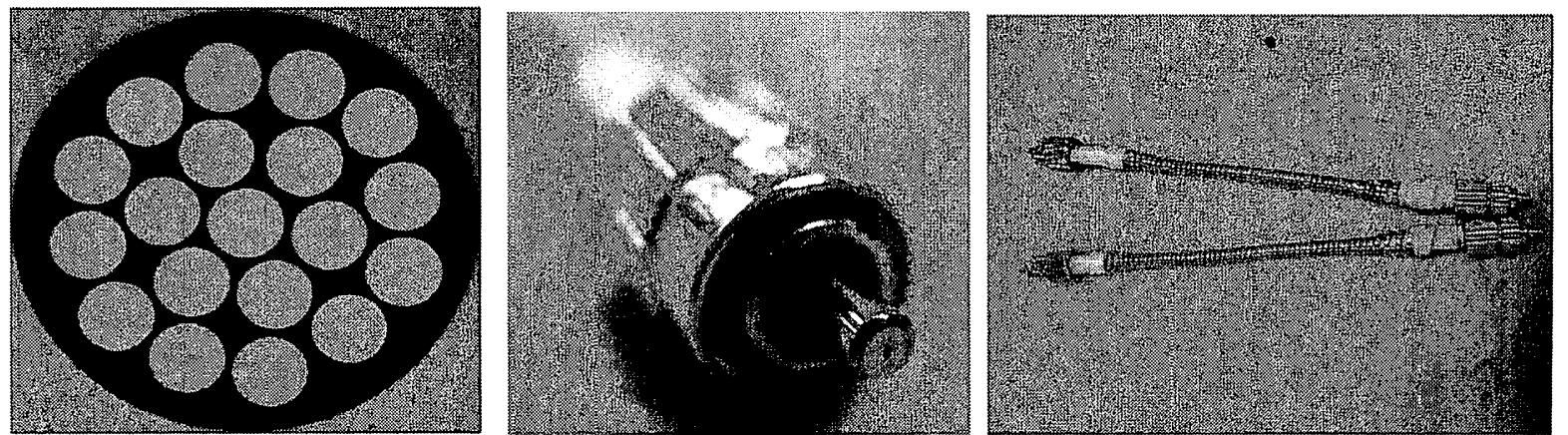

Figure 15: a) $200 \mathrm{X}$ magnification of a 19 optical fiber array end face ferrule in an FC connector, b) Close up of FC ferrule and connector, c) 19 fiber custom array technology.

Currently the group is developing new capabilities in the areas of customized arrays, high power terminations for fiber laser and laser transmission systems and high performance small form factor configurations for board interconnects.

\section{CONCLUSION}

The Photonics Group will continue to develop and evaluate various technologies for the upcoming missions identified in the NASA Decadal survey [23], interconnection for small form factor applications and for high performance and 
reliability missions such as the outlined for Constellation. We provide guidance to vendors for their flight builds as well as providing small volume customized versions for instrumentation and communication systems for vendors and other government agencies. Although commercial versions of the technologies described here may exist, most vendors and agencies still require specialized guidance especially with regards to the physics of failure when building high performance and high reliability optical subsystems for harsh environments.

\section{ACKNOWLEDGEMENT}

The group would like to thank all those who make our work successful: Marcellus Proctor, Jelila Mohammed, Patricia Friedberg, Kusum Sahu, John Day, Fred Huegal, Robert Lebair, Henning Leidecker, Adam Matuszeski, Mark Flanegan, Matt Showalter, Steve Schmidt, Luis Ramos-Izquierdo, John Cavanaugh, Denise Radliff, Bruce Meinhold, Amir Sadeghi, Darryl Lakins, Craig Tooley and Cathy Peddie (LRO Program Managers), the MSL team: Edward Miller, Chris Lindensmith, Richard Rainen, Charles Hayes, Roger Weins, Joe Mooney and Cheryl Provost from CeramOptec, W.L. Gore, Frederick Taugwalder from Diamond Switzerland, Diamond USA, Polymicro Technologies, Martin Seifert at Nufern, Sandia National Labs, Frank Hung, Jeffery Christiansen, Fred Orlando, Charles Chalfant, and Matt Leftwich from SPI, the ELC team Chris Smith, Oscar Gonzales, Ali Feizi, and most of all Ken LaBel and Mike Sampson (NEPP program managers) for funding the dissemination of this work.

\section{REFERENCES}

[1] Kenneth A. LaBel, Cheryl J. Marshall, Paul W. Marshall, Philip J. Luers, Robert A. Reed, Melanie N. Ott, Christina M. Seidleck, and Dennis J. Andrucyk, "On the Suitability of Fiber Optic Data Links in Space Radiation Environment: A Historical Scaling Technology Perspective," IEEE Aerospace Conference, Volume: 4, 1998, Page(s): 421-434.

[2] URL is http://nobelprize.org

[3] Ken LaBel, Update of reference [1],briefing at Marshall Space Flight Center, 1999.

[4] http://sunland.gsfc.nasa.gov/smex/sampex/

[5] Melanie N. Ott, "Validation of Commercial Fiber Optic Components for Aerospace Environments" SPIE Conference on Smart Structures and Materials, Smart Sensor Technology and Measurement Systems, Vol. 5758, March 2005. http://misspiggy.gsfc.nasa.gov/photonics.

[6] Susan Falvey's summary flowchart based on M. Ott, Components for Space Systems, Presentation for the Advanced Microelectronics and Photonics for Satellites Conference, AMAPS, Fayetteville, Arkansas June 23, 2004.

[7] Lisa McMurray, "Tests and results of active alignment fiber optic connectors for space usage," SPIE Conference on Photonics for Space Environments IV, Vol. 2811, 1996.

[8] Mark Flanegan, "Geoscience Laser Altimeter System (GLAS) Space Flight Instrument Fiber Optic System," International Society for Optical Engineering, SPIE Conference on Optical Devices for Fiber Communication II, Proceedings Vol. 4216, November 8, 2000, Boston.

[9] Melanie N. Ott, "Electron Induced Scintillation Testing of Commercially Available Optical Fibers for Space Flight," Nuclear and Space Radiation Effects Conference Data Workshop Proceedings, Norfolk, Virginia, July 1999.

[10] Melanie Ott, Joy Bretthauer, "Twelve Channel Optical Fiber Connector Assembly: From Commercial off the Shelf to Space Flight Use" International Society for Optical Engineering, Conference on Photonics for Space Environments VI, SPIE Proceedings Vol. 3440, 1998.

[11] Melanie N. Ott, Shawn Macmurphy, Patricia Friedberg, "Characterization of a twelve channel optical fiber, ribbon cable and MTP array connector assembly for space flight environments," International Society for Optical Engineering, 
SPIE Aerosense Conference Proceedings on Enabling Photonic Technologies for Aerospace and Applications IV, Vol. 4732, April 2002.

[12] Xiaodan "Linda" Jin, Melanie N. Ott, Frank V. LaRocca, Ronald M. Baker, Bianca E.N. Keeler, Patricia R. Friedberg, Richard F. Chuska, Mary C. Malenab, Shawn L. Macmurphy, "Space Flight Qualification on a Multi-Fiber Ribbon Cable and Array Connector Assembly," International Society for Optical Engineering, SPIE Optics and Photonics Conference on Photonics for Space Environments XI, Photonics Technologies for Radiation Environments II, Vol. 6308, August 2006.

[13] Melanie N. Ott, Marcellus Proctor, Matthew Dodson, Shawn Macmurphy, Patricia Friedberg, "Optical Fiber Cable Assembly Characterization for the Mercury Laser Altimeter," International Society for Optical Engineering, SPIE AeroSense Conference on Enabling Photonic Technologies for Aerospace Applications V, Proceedings Vol. 5104, April 2003.

[14] D. Barry Coyle, Paul. R. Stysley, "The High Output Maximum Efficiency Resonator (HOMER) Development for Long Life, Space-Based Altimetry,” IEEE, International Aerospace Conference, Montana, March 2006.

[15] X. Sun, G. A. Neumann, J. F. McGarry, T. W. Zagwodzki, J. F. Cavanaugh, J. J. Degnan, D. B. Coyle, D. R. Skillman, M. T. Zuber, D. E. Smith, "Laser Ranging between the Mercury Laser Altimeter and an Earth-based Laser Satellite Tracking Station over a 24-million-km Distance," OSA Annual Meeting, Tucson AZ, Oct. Proceedings, 2005.

[16] David E. Smith, Maria T. Zuber, Xiaoli Sun, Gregory A. Neumann, John F. Cavanaugh, Jan F. McGarry, Thomas W. Zagwodzki, “Two-Way Laser Link over Interplanetary Distance,” Science Magazine, Vol. 311, January 6, 2006.

[17] Lunar Reconnaissance Orbiter Website, http://lunar.gsfc.nasa.gov.

[18] Xiaodan "Linda" Jin, Melanie N. Ott, Frank V. LaRocca, Richard F. Chuska, Stephen M. Schmidt, Adam J. Matuszeski, Shawn L. Macmurphy, William J. Thomes, Robert C. Switzer "Space Flight Qualification on a Novel Fivefiber Array Assembly for the Lunar Orbiter Laser Altimeter (LOLA) at NASA Goddard Space Flight Center," SPIE Optics and Photonics Conference, Photonics Technology for Space Environments II, Vol. 6713, Aug 28, 2007.

[19] David E. Smith, 19th International Laser Ranging Workshop, Canberra Australia, Oct 16-20 2006.

[20] Melanie N. Ott, Xiaodan "Linda" Jin, Frank V. LaRocca, Adam J. Matuszeski, Richard F. Chuska, Shawn L. Macmurphy, "Requirements Validation Testing on the 7 Fiber Array Connector/Cable Assemblies for the Lunar Reconnaissance Orbiter (LRO)," Invited paper, SPIE Optics and Photonics Conference, Photonics Technology for Space Environments II, Vol. 6713, Aug 28, 2007.

[21] Melanie N. Ott, Robert Switzer, Richard Chuska, Frank LaRocca, William Joe Thomas, Shawn Macmuphy, "Development, Qualification, and Integration of the Optical fiber Array Assemblies for the Lunar Reconnaissance Orbiter," SPIE Optics and Photonics Conference, Nanophotonics and Macrophotonics for Space Environments II, Vol. 7095, San Diego CA, August 2008.

[22] http://mars.jpl.nasa.gov/msl/

[23] Farzin Amzajerdian, “The Expanding Role of LIDAR at NASA,” Photonics Spectra July 2008, pp 50 - 55. 